\title{
Study on Chuang Tzu's Attitude towards Death and Its Practical Significance
}

\author{
Changhong $\operatorname{Tian}^{1, \text { a }}$ \\ ${ }^{1}$ Pingxiang University, Pingxiang, Jiangxi, China, 337000 \\ a email
}

Keywords: Chuang Tzu, Attitude towards Death, Practical Meaning of Spirit

\begin{abstract}
Taoist life view has a naturalistic spirit, full of natural care. In the face of the fear of death and some of our own problems can not solve the problem, Chuang Tzu with free and easy state of mind to resolve it. Chuang Tzu think that can be treated by reason, reasoning; security at the Shun, the life and death placed outside; through the "South Wang Yue" to digest people for the psychological fear of death, get rid of people's obsession with survival; "Said its meaning", can "channel". Chuang Tzu in the "Chuang Tzu Tak de Fu" said: "life and death is also big, and not with the change." To follow the natural, rational and objective view of life and death; heart if the mirror, the heart should be, Good feelings and the relationship between reason; the object of the heart, not to materiality, respect for life itself; to no one, God without power, sage unknown, to reach the realm of adults. The actual boundaries of life and death and emotional boundaries have been Chuang Tzu to this unique philosophy of the break.
\end{abstract}

\section{Introduction}

Philosophy is a reflection of the activity. The most questionatic question is: what is the body of the world? who am I? Where did i come from? Where are you going? Are to look on the students, want to reduce the fear of death. But no dead, where is the born? Death is also the need for human evolution. People are only a limited number of individuals, human life is limited, one day will come to the end of life. Like to see the child was born, completely objective to know that he (she) will be to death, that he (her) alive for this life is for what? Everyone looks for the relative to their own infinite world, in the end to grasp the number of each person for their own ignorance of death and how should we face?

\section{The Attitude of Confucianism, Buddhism and Taoism to Death}

British Daniel. Defoe said: "fear of dangerous psychology than the danger itself is terrible ten thousand times." Then it can also be said that death and danger are not terrible, terrible is waiting for death and danger to the moment of arrival. Confucianism, Buddhism and Taoism are talking about how to treat death. Confucian "The Analects of Confucius" Confucius was asked to life and death, the child said: "unknown students, how to know death." Confucius said "life and death, wealth in the days." Confucianism pay more attention to the reality of social real life research, pay more attention to the existence of life and the relationship between the human environment. And Buddha, "asked the Buddha", I asked the Buddha: What is the definition of death? Buddha says death is an extension of life. We should not be afraid of death, on the contrary, we should praise death. There is no death, how to life? No death, how to reincarnation of the week after another? "Six ancestral altar" has words: "What is the Polo honey? This is the Western language, Tang to the other side. Interpretation of off life and death. Such as the water there is a wave, that is, the name of the shore. Departure no life and death, such as water often flow, that is, the other side, hence the name of Polo honey. "Buddha believes that from the shore to the other side, past life, causal cycle. Relative to the two, the author believes that the Taoist attitude is more realistic reference, Taoist life view is more naturalistic spirit, full of natural care. 


\section{The Attitude of Chuang Tzu to Death}

Chuang Tzu in the "Chuang Tzu know the North Tour" said that life between heaven and earth, as the horse crossed the pores, flying away. Compared with the heaven and earth universe, the length of human life is short and short. There shall be life and death, and there shall be life of death, and of life shall be born to death. For death everyone has to face. This is a great sorrow for an emotional person. How can we be kind and not tired? In the face of the fear of death and the face of some of our own role can not solve the problem, Chuang Tzu cultivated a free and easy state of mind to resolve it.

Spinoza said: "The more people understand the cause and effect of things, he will be more aware of the consequences of the incident, and reduce the resulting suffering." Taoism is also the case, through reason to love.

Chuang Tzu wife died, Hui Shi went to condolence, see Chuang Tzu not only cry, still drums and songs. This is Chuang Tzu's rationale. Many people only see Chuang Tzu wife died when the drums and songs, but did not notice that he said, "is the beginning of death, I can not have nothing!" My wife just died, how can I not sad The Fully embodies the Chuang Tzu wife side of the side, but behind through their own rational thinking figured out. Chuang Tzu went on to say that "there is no life, no one is born and is invisible, and is invisible, and there is no air." The life of man is because of gas gathering, human death is also because of the air, so get rid of the spirits of life and death for the fate of human life and death, only life and death as a natural phenomenon that life and death process is like a four-hour operation same. "People and Yan Ran sleep in the giant room, and I then then cry, since that does not pass the same life, it is also only." That is the way, Chuang Tzu self-made by the situation into reason, reasoning.

"Shi said the new language of any birthday" also mentioned when the state of Ruan Ji mother died. Article 9 said: Ruan Ji when the fury of the mother, steamed a dolphin, drinking two bucket, and then the way, bluntly: "poor carry on!" Had a number, due to hematemesis, waste a long time. Deng Yan, "Jin Ji" said: "Mother will die, and people go so, the other seeking, membership refused to stay and stay gambling, while drinking three bucket, cries one, hematemesis a few liters, "Ruan Ji and Chuang Tzu just the opposite, when the mother died, did not respond, calm and continue to play chess with people, betting, drinking meat, violation of ritual, but also against human nature. So, when his mother died, "on the 1st" and "vomiting blood", distraught, almost into the mad state, which is his feelings to the performance of sex. But also that Ruan Ji believe in the more famous more natural, hope that they can be free and easy to face life and death, but through this fact, he did not see through life and death, but was Chuang Tzu-shaped, and not their gods.

"Chuang Tzu health master" articles: the old slaughtered dead, Qin lost condolences, No. 3 out of ... ... Qin lost: "is the escape day times love, forget their own, the ancient that the escape The right to that is the emperor of the county solution. "Only peace of mind in a timely manner to adapt to changes in the mood of the music before the music is not the same time, Can not invade into the heart. People live with a lot of pain, such as being overwhelmed. Died down to heaven, it is God lifted your doldrums. Chuang-tzu by Qin lost his mouth, the person's birth as a time to come, the death of people as a matter of things, that can be safe, with Shun materialized, conform to the changes in life and death, sad music can not enter the heart, this Is to lift the suspension of the way. Secular crowd, do not live in the inverted state, the biggest yoke is the idea of their own life and death ----- fear of death and the tragedy of life trapped. If people can live and die like ----- floating from the air, floating away. In any case, do "safe at the Shun", the life and death placed outside, not subject to the vulgar, it is like hanging. Those who reach this realm is a life and death. Do not have to love, do not bother; do not fear, do not have music. Life is between heaven and earth, work and death are extremely natural things, should be frankly. Chuang Tzu said, "So good my life, is so good I die also." Living a sound life, but to enjoy the death of a complete; certainly raw, so sure to die; death value depends on born sure; Depends on giving birth.

In the "Chuang Tzu to music" chapter, talked about a dialogue with the skeleton. This time, Chuang Tzu personally battle, looks for a skeleton questioning. Chuang Tzu to Chu, see a pair of skeletons, " to horse hammer", to himself to ask questions, "the Master of the poor and for this 
reason? The son of the subjugation of things, ax of the punish And for this is the child will have a poor trip, the parents of the parents of the ugly and ugly for this? The child has the risk of frozen, and for this time the child's spring and autumn and so on? "Chuang Tzu to five lethal The reason is said, the best result than the "will be the spring of the child and this almost," the end of life only sleep. In front of the other four are not normal, are dead, no hospice. After that, their own "aid Calvary, pillow and lying." In the middle of the night, Chuang Tzu dream of the skeleton told him that no dead on the dead, under no minister, "Although the south of Wang Le, not too", "I can abandon the south of the king of music and complex for the world!" The opportunity to let him return to earth, he is also very reluctant. Chuang-tzu would like to use the "south of Wang Yue" to digest people for the psychological fear of death.

"Chuang Tzu homogeneous theory", talked about the beauty of Li's psychological activities. Li Ji is the son of Ai, when she wants to marry, "tears sobbing", cry so sad sad. And really to the king of the king of the palace, "and its as the king, and Wang with the basket $\mathrm{Mu}$, food and feed, and regret it sobbing." "To the evil husband and wife do not regret the beginning of the prayer!" Chuang Tzu Think, according to this situation, how do I know the dead people do not regret their own efforts to survive it? This is not so much with the Chuang Tzu said that death is better than life, as he would like to let people overcome the fear of death, Qi death, get rid of ordinary people on the survival of obsession.

In the "Chuang Tzu Pirates of the plantar" mentioned in the dialogue with the stolen plant also talked about life and death, this period of Chuang Tzu by the mouth of the palm of the mouth is very clear. "Life is a hundred years old, life is eighty years old, the next life is sixty years old," in addition to the disease, Thin life and death, which opened and laughed, but in January but only four or five days. "Human life and heaven and earth compared to just as" Qi Ji Chi Chi also. " From the perspective of the universe, such a short life exists, if you can not "say its meaning", you can not count "channel who also" the. We have to do "channel", we must learn to cherish the treatment of their own lives, and the same channel, can enjoy the younger year.

\section{Chuang Tzu's Attitude towards Death is of Reference Significance to the Real World}

Health and death represent the poles of the life process. "Health is also dead, death is also the beginning of life" means death, death means that students Life is dead, this is the existence of any natural phenomenon of life, human life is no exception. But life and death is the biggest and most stirring event in the life process. The reaction to it is extremely complex, especially death, and it is not easy for people to accept it frankly. People in the real world, there are different attitudes towards death. Some fear that even refused to die, that death can not be changed, they spend their lives to spend their lives; some that alive is a negative burden, a torture that only death is the liberation, resulting in prayer speed of death; Life and death to the fate, advocate obedience, natural attitude towards life and death. In fact, the students are accidental, death is inevitable, this is "when the self, when the death" within the meaning of justice. And we are born when the music and death when the sad, but because we will be born as "get", the death as "lost", that is, the existence of tangible things to look at life and death problems, so There are gains and losses, and further cause the joy and pain of emotion. Chuang Tzu in the "Chuang Tzu Germany and Germany," by the mouth of Confucius praised Wu Wang said: "life and death is also big carry on, and not with the change." Life and death is a big thing, but will not affect their own state of mind. Dada of the real people, will be deep in the way of access, fit in the context of change, and material assimilation, and the creators with the tour, regardless of life and death, all for its sexuality, physical shape, and the shape of the true and false From the shape, then my true will not leave, so there is no loss, no life without death, life and death double condemnation, gains and losses all obliterate, joy and feelings of how can we stay in the heart?

Follows the natural, rational and objective view of life and death. See through life and death, there is life there is death, no death or no life, life is the part of death, death is also another embodiment of life. Knowing that death is only a natural phenomenon, as to see the vegetation will be the same as a dry. To be plain to look at life and death, standing on the perspective of the 
universe Avenue, death is attributed to eternal, return to the road.

The "fate" or "limited" of life, and the cognitive "infinite" or infinite, together constitute a certain understanding of time, and this understanding must be on life and death conscious consciousness and thinking as a prerequisite, only in the kind of persecution between life and death in order to make people face limited and infinite confrontation, and make it really face the limitations of self, thus comprehending the meaning of the passage of time, and a clear timeliness to live in the existence of self Among them. Chuang Tzu will think deeply about the problems of life and death, and try to get through the limited and infinite boundaries, with "Tao Tong as one", "and things together", "swim in infinity" and so on, emphasizing its timeliness and eternity The "Who can not for the first, to the students for the ridge, to death for the Raji, know who survived the one who, I and my friend carry on." Sub-worship, sub-Yu, sub-pear, the child is the body to life and death One, and pay in the inverse In the child when the death of Sang, his friend Mencius anti, the piano and the song, "and the world of free gas." With the death of the child to further highlight the existence of the possibility of the possibility of existence. Which the Taoist character and the Confucian characters in the treatment of life and death differences table, the existence of the existence of the possibility of the existence of the way, and people consciously choose the survival of the relevant.

2, if the heart if the mirror. Things come to the heart, things to heart only. "To the heart of the mirror," like a mirror as the same, has been without any mark, not according to do not meet, to the heart should be, Learn to adjust their own feelings, so sad not hurt. Loved ones die, can not be sad, but pay attention to do a good grasp of the relationship between emotion and reason. Do not blew bone, has been immersed in the sadness can not extricate themselves. Pay attention to the balance between emotion and reason, not to lose. Do reason to reason, sad and not hurt.

3 , the cost of travel, not "easy to", respect for life itself. There are many people living in the community without awakening of life, the total "things in the material", the fame and fortune, status, wealth and other things outside the body looked very heavy, in fact, these are the loss of people's fundamental. For human life itself, those fame and fortune, status, wealth is only some foreign matter only, that is, we often say things outside the body. To take the boat, cherish life. Life in a hurry, only a few decades, lives to 90 years old, but also just over 30,000 days. To be beyond the points of all things and things of my points, so that together with all things, homogeneous things I, from the height of the universe into the nothing, no persistent spiritual state, to go beyond the life and death of the bitter and the phenomenon Travel, get spiritual freedom. Cherish life, start from their own, despite internal factors, regardless of external factors, grasp the present every day.

To people without their own, God no power, sage unknown, to reach the realm of adults. Chuang Tzu in the "Happy Tour" said: "Gu Yue, to people without their own, the people of God without power, sage unknown." Note that "saints, the kind of right ear, not enough to name it." Sparse said, "to the words of their body, the use of words, the words of the Word, so the language to the language, there is the language of God, the name of St., in fact, also Yi Yi Ling, so that the; , So that the gods; the name of the hundred things, so that the holy. One person above, which has three, want to function with the name of the Ming, so there are three of the other three people, it is the text by heaven and earth, the Royal "No reactive" is not for the community to do what "nameless" is not to the community to what, are no To be in society; "no self" is further left to their own. "Is" is the consciousness of existence, to the "no self", is the real "no wait", toward the infinite process of transcendence, which is adult The realm of the. Can do "things and not things", control things rather than being managed by things. The world of life requirements of a higher than one, from Yan Hui to go to Wei, Ye Gongzi Qi Qi, Yan Jingwei princes master three things, said to reach the soul of virtual spirit, beyond my state of "heart fasting", and Earthly, but have their own spiritual world "to travel to the heart" to achieve the heart to the heart, things to the heart of the "heart if the mirror", and all things together, and ultimately can reach "no people, God People without power, sage unknown "adult realm.

Chuang Tzu does not believe in the world after death, but also against the burial. This is in the "Chuang Tzu • column Royal Kou", the disciples made a thick burial of him, he replied, "I am heaven and earth for the coffin, with the sun and the moon for even Bi, stars for the Abas, all things 
for the delivery." Is this funeral also not enough? Chuang Tzu treat death is really really understand, see particularly transparent. Death in his eyes, but the normal law of the four seasons reincarnation, is a beautiful "butterfly dream". "If we can stand in the universe, standing outside of our individual to observe the death of words, then the boundaries of life and death disappeared." "The real life of the people, I do not know Wyatt, I do not know evil death; its out of the i斤r, its into the distance; Xi Ran, Xi Ran came only." The actual boundaries of life and death and emotional boundaries are Chuang Tzu to this unique philosophy Break through.

\section{References}

[1] [Song] Zhu Xi: "four chapters of the sentence set Note" [M]. Beijing: Zhonghua Book Company, 2010.

[2] [Qing] Yu Jiaxi release: "Shi said the new language" [M]. Beijing: Zhonghua Book Company, 2013.

[3] [Qing] Hu Wenying: "Chuang Tzu see Chuangzhuang on" [M]. Beijing: Zhonghua Book Company, 2011.

[4] [Qing] Guo Qingfan: "Chuang Tzu set release" [M]. Beijing: Zhonghua Book Company, 2013.

[5] Cui Dahua: "Chuang Tzu Yi solution" [M]. Beijing: Zhonghua Book Company, 2012.

[6] Fang Yong, Lu Yongpin: "Chuang Tzu interpretation" [M]. Chengdu: Bashu book club, 2004.

[7] Fang Yong: "Chuang Tzu appreciation dictionary" [M]. Shanghai: Shanghai Lexicographical Publishing House, 2010.

[8] Li Xia: "life and death wisdom: Taoist life view" [M]. Beijing: People's Publishing House, 2004.

[9] Wang Xiao fish: "Chuang Tzu within the new solution Chuang Tzu pass Shu Zheng" [M]. Beijing: Zhonghua Book Company, 2014. 